\title{
Resistência e Existência Indígena no Ensino Superior: Uma Análise de Eventos Étnicos na UnB
}

\author{
Gabriel Ribeiro Bizerril \\ Universidade de Brasília - UnB \\ e-mail: gabrielribeirob.16@gmail.com
}

Palavras-chave: Associação de Acadêmicos Indígenas da UnB (AAIUnB), eventos acadêmicos indígenas, Lei de cotas; ensino superior.

\section{Introdução}

A pesquisa analisou quatro eventos realizados sob a liderança dos estudantes indígenas da Universidade de Brasília, 0 " $1{ }^{\circ}$ Congresso Brasileiro de acadêmicos pesquisadores e profissionais indígenas" (2009), a "1 a Semana dos acadêmicos indígenas" (2010), " 2 a Semana dos acadêmicos indígenas" (2016) e a "3a Semana dos acadêmicos indígenas" (2017), na perspectiva do campo científico (Bourdieu, 1976), da ação política indígena (Ruano, 2013), da interculturalidade (Walsh, 2009) e dos debates sobre a centralidade dos eventos científicos (Targino e Neyra, 2006). A partir desse objeto, se problematiza a inserção desses estudantes na Universidade de Brasília.

Entende-se que tais eventos carregam uma ampla bagagem de informações, acadêmicas e políticas, que dizem a respeito dos desafios e das propostas de mudança com que o movimento indígena interpela a universidade brasileira, instituição excludente da diversidade étnica e cultural. Buscaram-se pontos comuns e divergentes mediante a comparação temporal e do conteúdo político das agendas dos eventos, acontecidos com até 8 anos de diferença.

\section{Metodologia}

Para abranger os objetivos da pesquisa e, frente as especificidades encontradas durante o trabalho de campo, se adotou a triangulação metodológica proposta por Duarte (2009). Trata-se de uma combinação de técnicas quantitativas e qualitativas, não restringindo a pesquisa à predominância de apenas uma forma específica, o que permitiu um olhar mais amplo ao objeto.

A pesquisa de campo sobre $01^{\circ}$ Congresso utilizou-se da análise documental, (Cellard (2008); para a compreensão da $1^{\text {a }}$ semana indígena se 
adotou a entrevista com atores chave (Boni e Quaresma (2005), a 2 ${ }^{\text {a }}$ Semana foi reconstruída mediante a análise documental e a observação participante e, na $3^{\text {a }}$ semana indígenas também se realizou observação participante. Este último instrumento permitiu atentar para às múltiplas dimensões desses eventos e enquadrá-los no contexto específico que se inscreveram.

\section{Resultados}

Foram analisados quatro eventos acadêmicos liderados por estudantes indígenas da UnB, no projeto de pesquisa foram previstos somente três. Essa ampliação do objeto empírico de pesquisa denota um achado metodológico que indicou a importância da observação participante como técnica de pesquisa que permite evidenciar categorias analíticas diluídas quando os eventos são analisados mediante a revisão documental.

No projeto também se propôs uma abordagem metodológica focada nessa revisão como eixo central da coleta de dados empíricos. Contudo, foi incorporado um rearranjo na perspectiva da triangulação de técnicas permitindo uma melhor compreensão do objeto de análise.

Elaboração de um artículo acadêmico ("Análise dos eventos acadêmicos indígenas na UnB na perspectiva da interculturalidade crítica") apresentado no evento científico (V Conversas da Kata) realizado na UnB no primeiro semestre de 2017.

\section{Conclusão/Discussão}

Os eventos indígenas analisados apresentam caraterísticas científicas, adotaram estrutura tradicional na forma de mesas, conferências e GT's e seguiram uma agenda pré-estabelecida. Porém ao mesmo tempo possuem o caráter de serem politizados, propiciando a reunião e debate entre indígenas sobre os empecilhos e desafios da sua inserção e permanência no ensino superior brasileiro. Portanto, por se tratarem de eventos indígenas em ambiente acadêmico, são formatados observando a idiossincrasia cientifica, embora possuam uma complexidade diferenciada demarcada pelas agendas políticas mobilizadas e pelas performances étnicas que as legitimam.

Durante esses eventos, os indígenas reivindicam que sua presença na universidade está se dando de forma forçosa, sem os devidos cuidados e especificidades que ela exige o Estado brasileiro não nota (e se nota ignora) que o ensino superior reproduz relações de dominação e exclusão. 


\section{Referências}

BOURDIEU, Pierre. O campo científico. Reproduzido de BOURDIEU, P. Le champ scientifique. Actes de Ia Recherche en Sciences Sociales, n. 2/3, jun. 1976, p. 88-104. Tradução de Paula Montero.

CELLARD, A. A análise documental. In: POUPART, J. et al. A pesquisa qualitativa: enfoques epistemológicos e metodológicos. Petrópolis, Vozes, 2008.

GODOY, A. S. Pesquisa qualitativa - tipos fundamentais, In: Revista de Administração de empresas, v.35, n.3, Mai./Jun. 1995b. p. 20 - 29.

RUANO, Elizabeth Ibarra. A MINGA (COLÔMBIA) E O AIR (BRASIL): ANÁLISE DO PROTESTO INDÍGENA EM PERSPECTIVA COMPARADA. In:XV Congresso Brasileiro de Sociologia, 2011, Curibita. Anais do XV Congresso Brasileiro de Sociologia, realizado em Curitiba-PR, de 26 a 29 de julho de 2011, 2011.

TARGINO, M. G; NEYRA, O. N. B. Dinâmica de apresentação de trabalhos em eventos científicos. Informação e Sociedade: Estudos, Paraíba, v 16, n 2, 2006. Disponível em: (http://www.ies.ufpb.br/ojs2/index.php/ies/article/view/621).

WALSH, Catherine. "Interculturalidad crítica y educación intercultural." Instituto Internacional de Integración del Convenio Andrés Bello, La Paz, 911 de marzo de 2009. 